Article

\title{
Predictors of Exercise Capacity in Patients with Hypertrophic Obstructive Cardiomyopathy
}

\author{
Joshua R. Smith ${ }^{1, * \mathbb{D}}$, Jose R. Medina-Inojosa ${ }^{1} \mathbb{D}$, Veronica Layrisse ${ }^{1,2}$, Steve R. Ommen ${ }^{1}$ and \\ Thomas P. Olson ${ }^{1}$ \\ 1 Division of Preventive Cardiology, Department of Cardiovascular Medicine, Mayo Clinic, Rochester, \\ MN 55095, USA; medinaInojosa.jose@mayo.edu (J.R.M.-I.); veronicall@sanjuanbautista.edu (V.L.); \\ ommen.steve@mayo.edu (S.R.O.); olsont.thomas2@mayo.edu or olson.thomas2@mayo.edu (T.P.O.) \\ 2 San Juan Bautista School of Medicine, Caguas, PR 00727, USA \\ * Correspondence: smith.joshua1@mayo.edu; Tel.: +1-507-422-0264
}

Received: 15 October 2018; Accepted: 14 November 2018; Published: 18 November 2018

\begin{abstract}
Hypertrophic obstructive cardiomyopathy (HOCM) patients exhibit compromised peak exercise capacity $\left(\mathrm{VO}_{2}\right.$ peak). Importantly, severely reduced $\mathrm{VO}_{2}$ peak is directly related to increased morbidity and mortality in these patients. Therefore, we sought to determine clinical predictors of $\mathrm{VO}_{2}$ peak in HOCM patients. HOCM patients who performed symptom-limited cardiopulmonary exercise testing between 1995 and 2016 were included for analysis. Peak $\mathrm{VO}_{2}$ was reported as absolute peak $\mathrm{VO}_{2}$, indexed to body weight and analyzed as quartiles, with quartile 1 representing the lowest $\mathrm{VO}_{2}$ peak. Step-wise regression models using demographic features and clinical and physiologic characteristics were created to determine predictors of HOCM patients with the lowest $\mathrm{VO}_{2}$ peak. We included $1177 \mathrm{HOCM}$ patients (age: $53 \pm 14$ years; BMI: $24 \pm 12 \mathrm{~kg} / \mathrm{m}^{2}$ ) with a $\mathrm{VO}_{2}$ peak of $18.0 \pm 5.6 \mathrm{~mL} / \mathrm{kg} / \mathrm{min}$. Significant univariate predictors of the lowest $\mathrm{VO}_{2}$ peak included age, female sex, New York Health Association (NYHA) class, BMI, left atrial volume index, E/e', E/A, hemoglobin, N-terminal pro b-type natriuretic peptide (NT-proBNP), and a history of diabetes, hypertension, stroke, atrial fibrillation, or coronary artery disease. Independent predictors of the lowest $\mathrm{VO}_{2}$ peak included age (OR, CI: 1.03, 1.02-1.06; $\left.p<0.0001\right)$, women $(4.66,2.94-7.47 ; p=0.001)$, a history of diabetes $(2.05,1.17-3.60 ; p=0.01)$, BMI $(0.94,0.92-0.96 ; p<0.0001)$, left atrial volume index $(1.07,1.05-1.21 ; p=0.04), \mathrm{E} / \mathrm{e}^{\prime}(1.05,1.01-1.08 ; p=0.004)$, hemoglobin $(0.76,0.65-0.88 ; p=0.0004)$, and NT-proBNP $(1.72,1.42-2.11 ; p<0.0001)$. These findings demonstrate that demographic factors (i.e., age and sex), comorbidities (e.g., diabetes and obesity), echocardiography indices, and biomarkers (e.g., hemoglobin and NT-proBNP) are predictive of severely compromised $\mathrm{VO}_{2}$ peak in HOCM patients.
\end{abstract}

Keywords: hypertrophic cardiomyopathy; exercise testing; exercise capacity

\section{Introduction}

Hypertrophic cardiomyopathy (HCM) is a commonly inherited heart disease affecting 1 in 500 individuals [1], with $\sim 70 \%$ of these patients developing the obstructive phenotype, hypertrophic obstructive cardiomyopathy (HOCM) [2]. Patients with HOCM have a greater risk of mortality and greater severity of heart failure than HCM patients without obstruction [3]. HCM patients with and without obstruction generally present with exertional dyspnea, fatigue, and reduced peak functional capacity [1]. Factors contributing to the diminished peak functional capacity include impaired stroke volume response, left ventricular systolic and diastolic dysfunction, chronotropic incompetence, and peripheral muscle changes [1,4-6]. 
Cardiopulmonary exercise testing (CPET) is recommended for HCM patients to determine the severity of exercise intolerance, and the responsible mechanisms [7,8]. CPET also has important, clinically useful prognostic utility in HCM [9-13]. Specifically, reduced peak oxygen consumption ( $\mathrm{VO}_{2}$ peak) in HCM patients is associated with greater mortality and more severe progression of heart failure $[9,10,12,13]$. Furthermore, obstruction is associated with a further reduction in $\mathrm{VO}_{2}$ peak in HCM $[9,10,14,15]$. HCM patients also exhibit numerous cardiovascular risk factors, including diabetes, arterial hypertension, and coronary artery disease $[9-11,16,17]$. However, the contribution of these cardiovascular risk factors to the worsening of $\mathrm{VO}_{2}$ peak in patients with $\mathrm{HOCM}$ is unknown. Therefore, in the present study we sought to determine the relationship(s) between demographic factors, comorbidities, and echocardiography indices with the compromised $\mathrm{VO}_{2}$ peak in $\mathrm{HOCM}$ patients.

\section{Experimental Section}

Study design: This was a retrospective observational study of 1177 consecutive patients with HOCM tested in a single center between 1995 and 2016. All patients included in this analysis performed symptom-limited CPET testing and a comprehensive transthoracic echocardiogram within one week. Clinical CPET and echocardiographic data were obtained from an institutional database. A random sample in the electronic medical record was reviewed independently and in duplicate by two investigators (J.M.I. and V.L.) to validate the research strategy. This study was approved by the Mayo Clinic Institutional Review Board, and all patients agreed to the use of their medical records for research.

Clinical and echocardiographic assessment: HOCM diagnosis was based on clinical and echocardiographic evaluation by a cardiologist, assessing evidence of myocardial hypertrophy in the absence of cardiac or systemic disease associated with hypertrophy. Systemic hypertension did not preclude HOCM diagnosis if the myocardial hypertrophy was greater than clinically expected from the systemic hypertension. All resting transthoracic echocardiogram measurements were performed according to the guidelines of the American Society of Echocardiography. Of note, continuous wave Doppler and the modified Bernoulli equation (i.e., gradient $=4 v^{2}$, where $v=$ peak velocity) were used to determine left ventricular outflow tract gradient. Echocardiographic evidence of HOCM included left ventricular hypertrophy (i.e., septal thickness $\geq 15 \mathrm{~mm}$ ) and left ventricular outflow gradient of $\geq 30 \mathrm{mmHg}$ [8]. If obstruction was not present at rest, provocation via Valsalva maneuver, amyl nitrite, and/or exercise was performed [8].

Cardiopulmonary exercise testing: Clinically indicated CPET was performed by exercise physiologists under the supervision of a cardiologist. Patients completed an institutionally designed incremental exercise protocol $[18,19]$ on a motor-driven treadmill (GE CASE, Milwaukee, WI, USA). Briefly, this protocol consisted of increasing two metabolic equivalents every two minutes until volitional fatigue $[18,19]$. To maximize generalizability and minimize potential for decompensation, cardiac medications were not withheld prior to CPET. Ventilatory and metabolic variables were measured during exercise (MGC Diagnostics, St. Paul, MN, USA). Peak $\mathrm{VO}_{2}$ was the highest $30 \mathrm{~s}$ averaged value, expressed as $\mathrm{L} / \mathrm{min}$ and $\mathrm{mL} / \mathrm{kg} / \mathrm{min}$. The percent $(\%)$ predicted peak $\mathrm{VO}_{2}$ was reported using the FRIEND equation [20], and a \% predicted peak $\mathrm{VO}_{2}$ of $<80 \%$ was defined as abnormal $[13,15,21,22]$. Abnormal $\mathrm{VO}_{2}$ slope change was determined by a plateau in the $\mathrm{VO}_{2}$ versus time relationship, assessed by visual inspection. For patients not prescribed beta blocker therapy, peak heart rate was predicted using 220 - age. For patients on beta blocker therapy, $119+(0.5 \times$ resting heart rate $)-(0.5 \times$ age $)$ was used to determine predicted peak heart rate [23]. The $\mathrm{O}_{2}$ pulse $(\mathrm{mL} / \mathrm{beat})$ was determined by dividing $\mathrm{VO}_{2}$ by heart rate. The predicted peak $\mathrm{O}_{2}$ pulse was calculated by dividing the predicted $\mathrm{VO}_{2}$ peak by the predicted peak heart rate [19]. The $\mathrm{O}_{2}$ pulse slope change was assessed visually as the relationship between $\mathrm{O}_{2}$ pulse versus time. An abnormal $\mathrm{O}_{2}$ pulse was defined as a plateau in $\mathrm{O}_{2}$ pulse during exercise. Forced expiratory volume in $1 \mathrm{~s}\left(\mathrm{FEV}_{1}\right)$ (reported as $\%$ predicted) and breathing reserve were determined according to ATS/ERS guidelines [24]. 
Statistical analysis: Statistical analyses were performed using JMP software version 13.0 (SAS Institute Inc., Cary, NC, USA). Variables are presented as mean \pm standard deviation (SD) or absolute number of patients (\% of total sample) and were compared using one-way analysis of variance, Pearson chi-square test, or Fisher's exact test accordingly. Normality was assessed by visual assessment. Univariate and multivariate logistic regression models were created to test for clinical and echocardiographic predictors of low peak relative $\mathrm{VO}_{2}$. Based on previous studies $[9,13,15,21]$, we anticipated that the majority of our sample would have an abnormal peak $\mathrm{VO}_{2}$. Therefore, we grouped our sample in evenly distributed quartiles according to peak $\mathrm{VO}_{2}$ using the lowest (i.e., quartile 1) as the referent group in a similar manner as Coats et al. [12]. Univariate modeling was performed adjusting for age, sex, clinical, and echocardiographic factors known to potentially affect peak $\mathrm{VO}_{2}$, and those that were significant were included in the final multivariate modeling. Odds ratio (OR) and 95\% confidence intervals (CIs) are presented. Missing data were handled by omission from final models. Statistical significance was set at $p<0.05$.

\section{Results}

The sample population included 676 men and 501 women, and the mean age was $53 \pm 14$ years. Demographics, clinical characteristics, and cardiovascular risk factors according to $\mathrm{VO}_{2}$ quartiles (quartile 1: $\leq 14.14$; quartile 2: 14.15-17.70; quartile 3: $17.71-21.51$; quartile $4: \geq 21.52 \mathrm{~mL} / \mathrm{kg} / \mathrm{min}$ ) are presented in Table 1. Significant differences across quartiles were present for age, height, weight, BMI, FEV 1 (\% predicted), hemoglobin, NT-proBNP, sex, New York Health Association (NYHA) class, dyslipidemia, smoking history, and beta blocker use. Resting echocardiographic data stratified by $\mathrm{VO}_{2}$ peak quartile are presented in Table 2. Left ventricular ejection fraction, septum thickness, medial E/e', and mitral E/A were significantly different across the quartiles. Table 3 shows the peak CPET data stratified by peak $\mathrm{VO}_{2}$. The average $\mathrm{VO}_{2}$ peak for the entire sample population was $18.0 \pm 5.6 \mathrm{~mL} / \mathrm{kg} / \mathrm{min}$, with $1172(99.6 \%)$ of the HOCM patients achieving $\leq 80 \%$ predicted $\mathrm{VO}_{2}$ peak. At peak exercise, significant differences were present in treadmill time, $\mathrm{VO}_{2}$, respiratory exchange ratio, heart rate, breathing reserve, $\mathrm{O}_{2}$ pulse, $\%$ predicted $\mathrm{O}_{2}$ pulse, $\mathrm{V}_{\mathrm{E}} / \mathrm{VCO}_{2}$, abnormal $\mathrm{VO}_{2}$ slope, and abnormal $\mathrm{O}_{2}$ pulse slope across quartiles.

Table 1. Characteristics of the study population.

\begin{tabular}{|c|c|c|c|c|c|c|}
\hline & \multicolumn{5}{|c|}{$\mathrm{VO}_{2}$ peak $(\mathrm{mL} / \mathrm{kg} / \mathrm{min})$} & \multirow[b]{2}{*}{$p$-Value } \\
\hline & $\leq 14.14$ & $14.15-17.70$ & $17.71-21.51$ & $\geq 21.52$ & All Patients & \\
\hline $\mathrm{n}$ & 294 & 294 & 295 & 294 & 1177 & \\
\hline Age (years) & $50 \pm 15$ & $50 \pm 15$ & $54 \pm 14$ & $56 \pm 14$ & $53 \pm 14$ & $<0.001$ \\
\hline Height $(\mathrm{cm})$ & $171 \pm 10$ & $173 \pm 10$ & $172 \pm 10$ & $170 \pm 10$ & $171 \pm 10$ & 0.003 \\
\hline Weight (kg) & $94 \pm 22$ & $93 \pm 20$ & $90 \pm 20$ & $84 \pm 20$ & $91 \pm 21$ & 0.04 \\
\hline BMI $\left(\mathrm{kg} / \mathrm{m}^{2}\right)$ & $22 \pm 11$ & $23 \pm 10$ & $24 \pm 11$ & $28 \pm 13$ & $24 \pm 12$ & $<0.001$ \\
\hline $\mathrm{FEV}_{1}(\%$ pred. $)(\mathrm{n}=532)$ & $74 \pm 19$ & $82 \pm 18$ & $91 \pm 16$ & $95 \pm 17$ & $85 \pm 19$ & $<0.001$ \\
\hline Hemoglobin $(\mathrm{g} / \mathrm{dL})$ & $13.3 \pm 1.5$ & $14.0 \pm 1.4$ & $14.5 \pm 1.2$ & $14.8 \pm 1.3$ & $14.1 \pm 1.5$ & $<0.001$ \\
\hline NT-proBNP $(\mathrm{pg} / \mathrm{mL}) *$ & $\begin{array}{c}1110 \\
(470-2264)\end{array}$ & $\begin{array}{c}714 \\
(285-1417)\end{array}$ & $\begin{array}{c}620 \\
(236-1151)\end{array}$ & $\begin{array}{c}420 \\
(169-1092)\end{array}$ & $\begin{array}{c}661 \\
(259-1385)\end{array}$ & $<0.001$ \\
\hline \multicolumn{7}{|l|}{ Sex } \\
\hline Men & $175(60 \%)$ & $196(67 \%)$ & 175 (59\%) & $130(44 \%)$ & $676(57 \%)$ & \multirow{2}{*}{$<0.001$} \\
\hline Women & $119(40 \%)$ & $98(33 \%)$ & $120(41 \%)$ & $164(56 \%)$ & $501(43 \%)$ & \\
\hline \multicolumn{7}{|l|}{ NYHA Class } \\
\hline I & $4(1 \%)$ & $1(0.4 \%)$ & $3(1 \%)$ & $7(3 \%)$ & $15(1 \%)$ & \multirow{4}{*}{0.01} \\
\hline II & $22(8 \%)$ & 40 (14\%) & 32 (11\%) & $53(19 \%)$ & 147 (13) & \\
\hline III & $242(84 \%)$ & $236(84 \%)$ & $242(86 \%)$ & $202(74 \%)$ & $922(82 \%)$ & \\
\hline IV & $20(7 \%)$ & $5(2 \%)$ & $5(2 \%)$ & $10(4 \%)$ & $40(4 \%)$ & \\
\hline \multicolumn{7}{|l|}{ Diabetes } \\
\hline No history & $261(89 \%)$ & $271(92 \%)$ & 272 (92\%) & $269(91 \%)$ & 1073 (91\%) & \multirow[b]{2}{*}{0.40} \\
\hline History & $33(11 \%)$ & $23(8 \%)$ & $23(8 \%)$ & $25(9 \%)$ & $104(9 \%)$ & \\
\hline
\end{tabular}


Table 1. Cont.

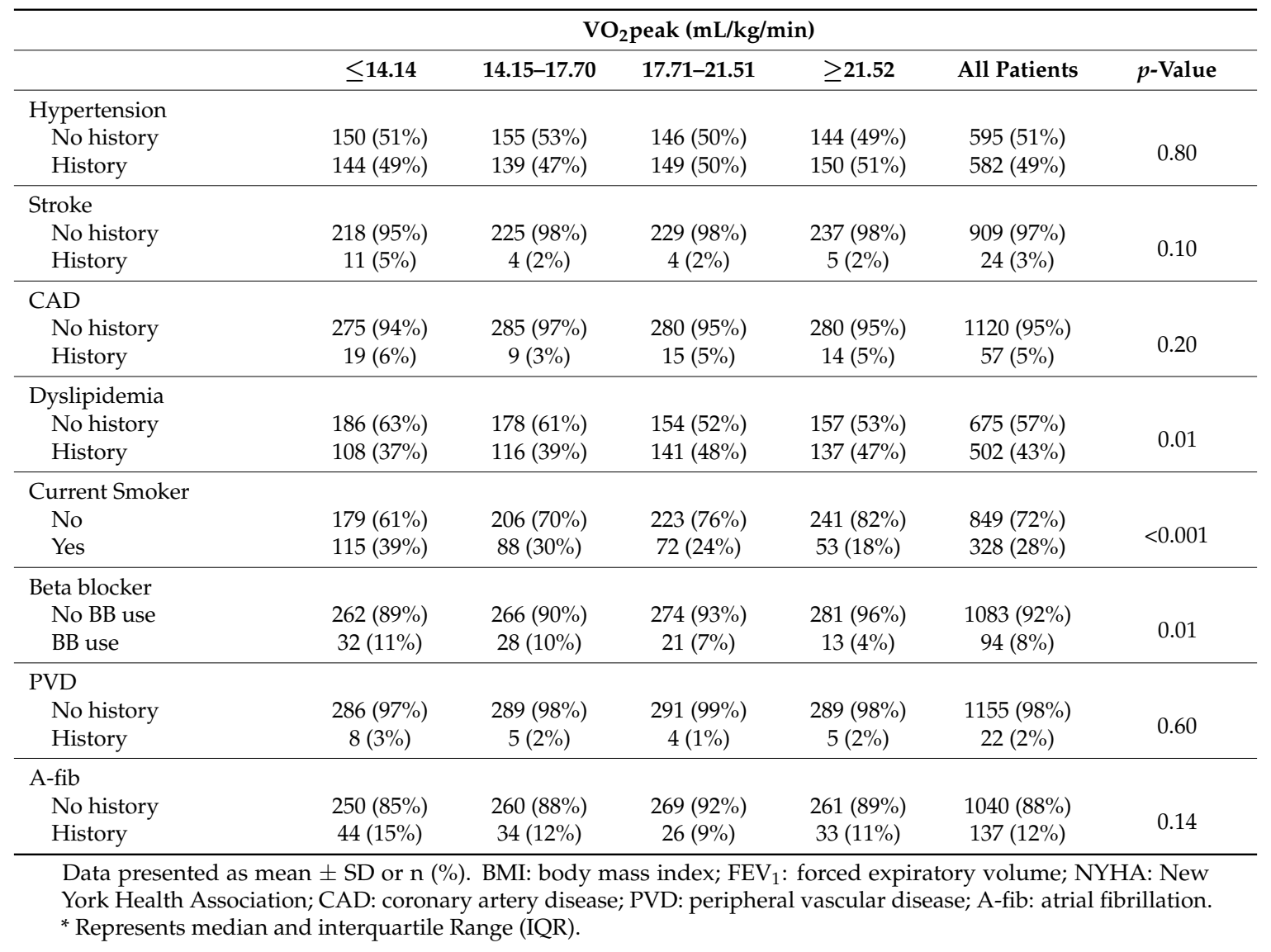

Table 2. Echocardiographic data stratified by peak $\mathrm{VO}_{2}$.

\begin{tabular}{|c|c|c|c|c|c|c|}
\hline & \multicolumn{5}{|c|}{$\mathrm{VO}_{2}$ peak $(\mathrm{mL} / \mathrm{kg} / \mathrm{min})$} & \multirow[b]{2}{*}{$p$-Value } \\
\hline & $\leq 14.14$ & 14.15-17.70 & $17.71-21.51$ & $\geq 21.52$ & All Patients & \\
\hline Left ventricular ejection fraction $(\%)(n=1177)$ & $66 \pm 9$ & $67 \pm 8$ & $68 \pm 7$ & $68 \pm 7$ & $67 \pm 8$ & $<0.001$ \\
\hline Septum $(\mathrm{mm})(\mathrm{n}=1177)$ & $19 \pm 6$ & $18 \pm 5$ & $17 \pm 5$ & $18 \pm 5$ & $18 \pm 5$ & 0.03 \\
\hline LVOT gradient $(\mathrm{mmHg})(\mathrm{n}=905)$ & $44 \pm 31$ & $40 \pm 30$ & $39 \pm 30$ & $40 \pm 31$ & $40 \pm 30$ & 0.07 \\
\hline Left atrial volume index $\left(\mathrm{mL} / \mathrm{m}^{2}\right)(\mathrm{n}=1177)$ & $38 \pm 12$ & $38 \pm 13$ & $38 \pm 13$ & $37 \pm 17$ & $38 \pm 14$ & 0.90 \\
\hline Medial E/e' ratio $(n=1016)$ & $20 \pm 10$ & $18 \pm 8$ & $18 \pm 9$ & $17 \pm 8$ & $18 \pm 9$ & $<0.001$ \\
\hline Mitral E/A ratio $(\mathrm{n}=1087)$ & $1.4 \pm 0.8$ & $1.2 \pm 0.6$ & $1.2 \pm 0.6$ & $1.2 \pm 0.6$ & $1.3 \pm 0.7$ & $<0.001$ \\
\hline
\end{tabular}

Data presented as mean \pm SD. LVOT: left ventricular outflow tract; $\mathrm{E} / \mathrm{e}^{\prime}$ : ratio of the peak transmitral inflow velocity

(E) to the peak mitral annular velocity $\left(\mathrm{e}^{\prime}\right)$; E/A: ratio of E to late transmitral flow velocity (A).

Table 3. Peak cardiopulmonary testing data stratified by peak $\mathrm{VO}_{2}$.

\begin{tabular}{|c|c|c|c|c|c|c|}
\hline & \multicolumn{5}{|c|}{$\mathrm{VO}_{2}$ peak $(\mathrm{mL} / \mathrm{kg} / \mathrm{min})$} & \multirow[b]{2}{*}{$p$-Value } \\
\hline & $\leq 14.14$ & 14.15-17.70 & $17.71-21.51$ & $\geq 21.52$ & All Patients & \\
\hline Treadmill time (min) & $4.8 \pm 1.6$ & $6.0 \pm 1.3$ & $7.3 \pm 1.5$ & $8.9 \pm 1.5$ & $6.7 \pm 2.1$ & $<0.001$ \\
\hline Relative $\mathrm{VO}_{2}(\mathrm{~mL} / \mathrm{kg} / \mathrm{min})$ & $11.4 \pm 2.2$ & $16.0 \pm 1.0$ & $19.4 \pm 1.1$ & $25.4 \pm 3.7$ & $18.0 \pm 5.6$ & $<0.001$ \\
\hline Absolute $\mathrm{VO}_{2}(\mathrm{~L} / \mathrm{min})$ & $1.0 \pm 0.3$ & $1.5 \pm 0.4$ & $1.8 \pm 0.4$ & $2.2 \pm 0.5$ & $1.6 \pm 0.6$ & $<0.001$ \\
\hline$\%$ Predicted peak $\mathrm{VO}_{2}$ & $36 \pm 8$ & $40 \pm 8$ & $44 \pm 7$ & $48 \pm 7$ & $42 \pm 9$ & $<0.001$ \\
\hline Respiratory exchange ratio & $1.12 \pm 0.14$ & $1.16 \pm 0.11$ & $1.16 \pm 0.11$ & $1.16 \pm 0.10$ & $1.15 \pm 0.12$ & 0.002 \\
\hline Heart rate (beats/min) & $111 \pm 24$ & $123 \pm 24$ & $131 \pm 24$ & $138 \pm 23$ & $126 \pm 25$ & $<0.001$ \\
\hline $\mathrm{O}_{2}$ pulse $(\mathrm{mL} /$ beat $)$ & $11 \pm 4$ & $13 \pm 4$ & $14 \pm 4$ & $14 \pm 5$ & $13 \pm 4$ & $<0.001$ \\
\hline$\%$ Predicted $\mathrm{O}_{2}$ pulse & $45 \pm 10$ & $54 \pm 9$ & $60 \pm 9$ & $70 \pm 12$ & $58 \pm 13$ & $<0.001$ \\
\hline $\mathrm{V}_{\mathrm{E}} / \mathrm{VCO}_{2}$ & $38 \pm 10$ & $33 \pm 6$ & $31 \pm 5$ & $31 \pm 5$ & $33 \pm 7$ & $<0.001$ \\
\hline Breathing reserve $(\%)(n=532)$ & $54 \pm 17$ & $56 \pm 15$ & $59 \pm 15$ & $61 \pm 15$ & $57 \pm 16$ & 0.0048 \\
\hline Abnormal $\mathrm{VO}_{2}$ slope change $(\mathrm{n}=923)$ & $146(70 \%)$ & $124(54 \%)$ & $116(48 \%)$ & $62(26 \%)$ & $448(49 \%)$ & $<0.001$ \\
\hline Abnormal $\mathrm{O}_{2}$ pulse slope change $(\mathrm{n}=919)$ & $140(68 \%)$ & $136(59 \%)$ & $118(48 \%)$ & $71(30 \%)$ & $465(51 \%)$ & $<0.001$ \\
\hline
\end{tabular}


Figure 1 shows the univariate predictors of $\mathrm{VO}_{2}$ peak in HOCM patients. Age $(p<0.0001)$, female sex $(p<0.0001)$, NYHA class $(p=0.0003)$, BMI $(p=0.03)$, hemoglobin $(<0.0001)$, NT-proBNP $(p<0.0001)$, left atrial volume index $(p=0.006), \mathrm{E} / \mathrm{e}^{\prime}(p<0.0001), \mathrm{E} / \mathrm{A}(p<0.0001)$, as well as a history of diabetes $(p<0.0001)$, atrial fibrillation $(p=0.04)$, hypertension $(p<0.0001)$, stroke $(p=0.01)$, and coronary artery disease $(p=0.02)$ were identified as significant predictors of the lowest $\mathrm{VO}_{2}$ peak (i.e., quartile 1). Left ventricular ejection fraction, septum thickness, left ventricular outflow tract gradient, dyslipidemia, smoking history, beta blocker use, and a history of peripheral vascular disease were not significant predictors of $\mathrm{VO}_{2}$ peak (all $p>0.14$ ). Figure 2 shows the multivariate predictors of $\mathrm{VO}_{2}$ peak in HOCM patients. Multivariate analysis identified age $(p<0.0001)$, female sex $(p=0.001)$, a history of diabetes $(p=0.01)$, BMI $(p<0.0001)$, left atrial volume index $(p=0.04), \mathrm{E} / \mathrm{e}^{\prime}(p=0.004)$, hemoglobin $(p=0.0004)$, and NT-proBNP $(p<0.0001)$ as significant independent predictors of the lowest $\mathrm{VO}_{2}$ peak in $\mathrm{HOCM}$ patients.

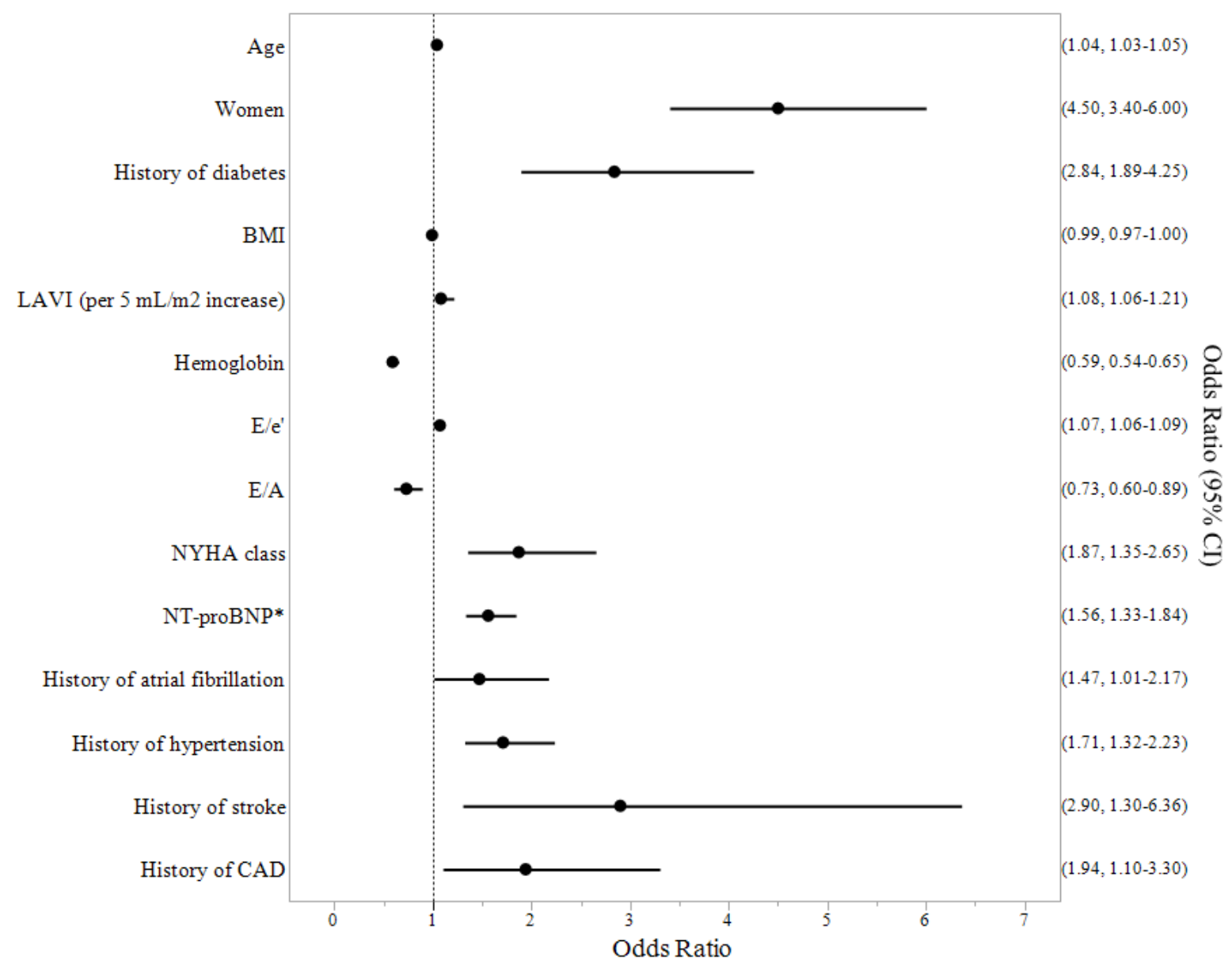

Figure 1. Univariate predictors of $\mathrm{VO}_{2}$ peak in hypertrophic obstructive cardiomyopathy (HOCM) patients. Significant predictors of the lowest $\mathrm{VO}_{2}$ peak were age, female sex, $\mathrm{BMI}$, left atrial volume index (LAVI, per $5 \mathrm{~mL} / \mathrm{m}^{2}$ increase), hemoglobin, E/e', E/A, NYHA class, NT-proBNP, and histories of atrial fibrillation, hypertension, stroke, and coronary artery disease (CAD). ${ }^{*}$ per each SD increase. Odds ratio and $95 \%$ confidence interval shown for each variable. 


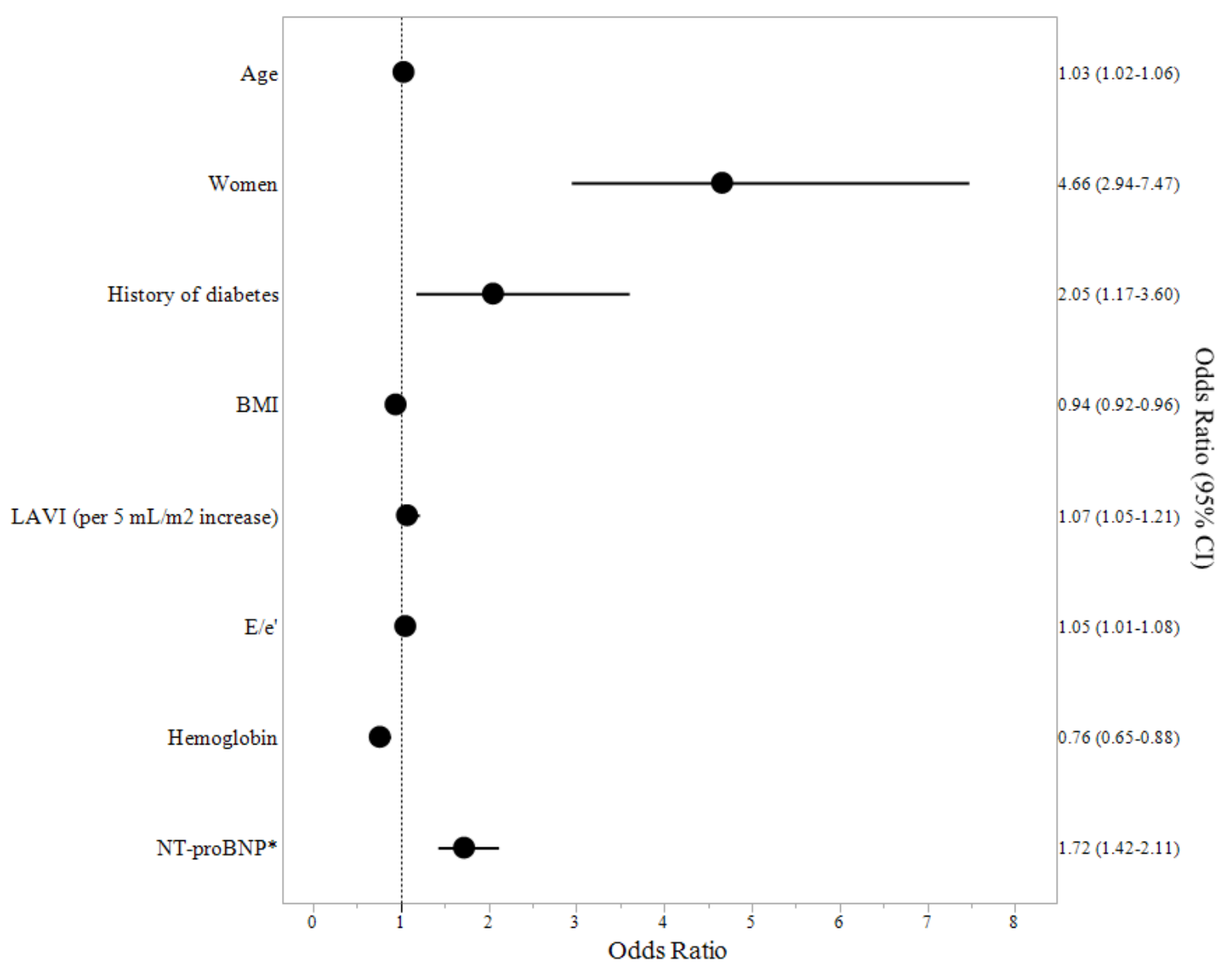

Figure 2. Multivariate predictors of $\mathrm{VO}_{2}$ peak in $\mathrm{HOCM}$ patients. Significant independent predictors of the lowest $\mathrm{VO}_{2}$ peak were age, female sex, a history of diabetes, BMI, left atrial volume index (LAVI, per $5 \mathrm{~mL} / \mathrm{m}^{2}$ increase), E/e', hemoglobin, and NT-proBNP. * per SD increase. Odds ratio and $95 \%$ confidence interval are shown for each variable.

\section{Discussion}

Major findings: In the present study, we determined the clinical predictors of peak exercise capacity in asymptomatic and symptomatic patients with HOCM. The novel finding of our investigation was that severely reduced exercise capacity was independently associated with female sex, a history of diabetes, age, body mass index, and echocardiography variables. Because diminished exercise capacity is predictive of mortality $[9,12]$, the present findings highlight the critical importance of clarifying demographics and optimizing cardiovascular risk factors in HOCM patients.

Predictors of $\mathrm{VO}_{2}$ peak: Patients with HCM generally exhibit reduced exercise capacity. In the present study, we found that nearly $100 \%$ of the HOCM patients had reduced exercise capacity (as indicated by $\mathrm{VO}_{2}$ peak $<80 \%$ predicted). This prevalence of $\mathrm{HOCM}$ patients with an abnormal $\mathrm{VO}_{2}$ peak was substantially greater than previously reported in studies with HCM patients (i.e., 39-70\%) $[9,13,15,21]$. As obstruction is an independent predictor of reduced exercise capacity for these patients $[9,10,14,15]$, a likely explanation for the greater prevalence of abnormal peak exercise capacity in the present study is the diagnosed presence of obstruction in all of our patients, while previous studies have incorporated a subset of HCM with obstruction. Moreover, we found that symptoms as indicated by NYHA class were not independently predictive of diminished exercise capacity. These findings are in line with previous studies reporting that symptoms generally underestimate the severity of exercise intolerance in these patients $[1,9,10,13,15,21]$. 
In the present study, the strongest independent predictor of compromised exercise capacity in HOCM patients was female sex. Specifically, women were $\sim 5$ times more likely to have a severely reduced $\mathrm{VO}_{2}$ peak compared to men. Furthermore, women had a lower peak $\mathrm{O}_{2}$ pulse compared to men (10 vs. $15 \mathrm{~mL} /$ beat, $p<0.01)$. In agreement, most studies with HCM patients (with only a subset exhibiting obstruction) have found that female sex is predictive of reduced exercise capacity $[13,14,17,21]$. For example, Magri et al. found that male sex was independently associated with higher peak $\mathrm{VO}_{2}$ in $180 \mathrm{HCM}$ patients $(\beta=2.84)$ [21]. These findings have important clinical implications, as exercise capacity is predictive of survival in HCM. In fact, a recent study in $3673 \mathrm{HCM}$ patients found that female sex was associated with greater risk of mortality when analyses were adjusted for cardiovascular comorbidities, age, and symptoms [17]. Furthermore, women with HCM have more symptoms, greater left ventricular outflow tract obstruction, and an increased risk for the development of overt heart failure compared to men $[12,17,25,26]$. The mechanism(s) underlying the sex differences reported in exercise capacity, prognosis, and mortality in these patients are not currently known, but are likely to involve social, genetic, and/or endocrine factors [26]. For example, it has been hypothesized that HOCM is misdiagnosed in women due to a variety of factors (e.g., women being less familiar with their cardiovascular risk [27]), resulting in delayed treatment and, subsequently, more severely advanced disease when an accurate diagnosis does occur [17].

A history of diabetes was the second strongest predictor of compromised exercise capacity in HOCM patients. The prevalence of diabetes in the present study $(\sim 9 \%)$ was in line with previous studies of HCM patients (3-16\%) [9-11,16,28]. In support of the relationship between diabetes and reduced exercise capacity in HOCM, diabetes is independently associated with cardiac hypertrophy (often termed "diabetic cardiomyopathy"), compromised systolic and diastolic function, and risk of heart failure [29,30]. Multiple interrelated mechanisms have been implicated in diabetic cardiomyopathy, including fibrosis, mitochondrial dysfunction, apoptosis, oxidative stress, inflammation, and microvascular dysfunction [29,31]. For example, it has been suggested that hyperglycemia-induced increases in advanced glycation end product formation impair collagen degradation, resulting in myocardial stiffness [32]. Future studies are warranted to determine the mechanisms by which diabetes contributes to exercise intolerance in HOCM patients.

Left ventricular dysfunction, as indicated by left atrial index and $\mathrm{E} / \mathrm{e}^{\prime}$, was also predictive of impaired exercise capacity, with BMI and age adding additional predictive utility (OR: 0.96-1.06). These findings coincide with previous studies reporting relationships between indices of diastolic dysfunction (e.g., left atrial index, E/e', and E/A) and impaired exercise capacity in HCM patients [33-36]. Possible underlying mechanisms responsible for the significant associations presented herein include exaggerated increases in cardiac filling pressures, pulmonary congestion, and pulmonary hypertension [37,38].

Clinical implications: HCM is a complex, highly heterogeneous disease in which left ventricular outflow tract obstruction worsens prognosis. CPET is important in HCM management because previous studies have suggested that symptoms are poor predictors of exercise capacity. Furthermore, CPET provides important mechanistic insight into the underlying causes of exercise intolerance, as well as providing prognostic value, in HCM. The findings of the present study are clinically relevant, and indicate the importance of clinically-determined demographic information and cardiovascular risks factors, specifically female sex and a history of diabetes, in predicting reduced exercise capacity. In addition, these findings provide specific clinical parameters that can be managed in order to ameliorate the severely impaired exercise capacity in these patients. Whether prevention of diabetes results in improved exercise tolerance and subsequently better prognosis and reduced mortality risk in HOCM patients is unknown.

Study limitations: The present study was retrospective and performed at a single center, and was thus susceptible to sources of bias associated with all retrospective analyses. As this study was performed in a high-volume tertiary referral center, the symptoms and exercise intolerance experienced by these HOCM patients may be more severe than in HOCM patients in the general population. It is 
important to note that $\sim 15 \%$ of this large study population were asymptomatic or mildly symptomatic (i.e., NYHA I or II), which does provide these findings with additional generalizability. In addition, optimally treated HOCM patients were included in the present study. Thus, additional studies are necessary to determine if these associations exist in untreated, newly diagnosed HOCM patients. Left ventricular dimensions, right ventricular function, and pulmonary pressures were not included in the present study. Based on the significant associations between $\mathrm{E} / \mathrm{e}^{\prime}$ and left atrial volume index with lowest $\mathrm{VO}_{2}$ peak, future studies are needed to investigate the underlying mechanisms by which diastolic dysfunction impairs peak exercise capacity in HOCM patients. Lastly, the physiologic mechanisms by which female sex and a history of diabetes contribute to exercise intolerance in HOCM were not tested in the present study, and warrant future investigation.

\section{Conclusions}

This large HOCM study population demonstrated that demographic factors (i.e., female sex), echocardiography variables, and cardiovascular risk factors (i.e., BMI and a history of diabetes) predict exercise intolerance. These findings demonstrate the importance of considering clinical and echocardiographic cardiovascular risk factors when performing CPET in HOCM patients.

Author Contributions: J.R.S., J.R.M.-I., V.L., S.R.O., and T.P.O. were all involved in the conceptualization of the study, data collection and analysis, and preparation of the manuscript drafts. All authors read and approved the final version of the paper.

Funding: This work was supported by the National Institutes of Health (R25-HL092621 and HL-126638RS to TPO) and American Heart Association (18POST3990251 to JRS).

Conflicts of Interest: The authors declare no conflicts of interest.

\section{References}

1. Magri, D.; Santolamazza, C. Cardiopulmonary Exercise Test in Hypertrophic Cardiomyopathy. Ann. Am. Thorac. Soc. 2017, 14, S102-S109. [CrossRef] [PubMed]

2. Maron, M.S.; Olivotto, I.; Zenovich, A.G.; Link, M.S.; Pandian, N.G.; Kuvin, J.T.; Nistri, S.; Cecchi, F.; Udelson, J.E.; Maron, B.J. Hypertrophic cardiomyopathy is predominantly a disease of left ventricular outflow tract obstruction. Circulation 2006, 114, 2232-2239. [CrossRef] [PubMed]

3. Maron, M.S.; Olivotto, I.; Betocchi, S.; Casey, S.A.; Lesser, J.R.; Losi, M.A.; Cecchi, F.; Maron, B.J. Effect of left ventricular outflow tract obstruction on clinical outcome in hypertrophic cardiomyopathy. N. Engl. J. Med. 2003, 348, 295-303. [CrossRef] [PubMed]

4. Lele, S.S.; Thomson, H.L.; Seo, H.; Belenkie, I.; McKenna, W.J.; Frenneaux, M.P. Exercise capacity in hypertrophic cardiomyopathy. Role of stroke volume limitation, heart rate, and diastolic filling characteristics. Circulation 1995, 92, 2886-2894. [CrossRef] [PubMed]

5. Jones, S.; Elliott, P.M.; Sharma, S.; McKenna, W.J.; Whipp, B.J. Cardiopulmonary responses to exercise in patients with hypertrophic cardiomyopathy. Heart 1998, 80, 60-67. [CrossRef] [PubMed]

6. Kjaergaard, J.; Johnson, B.D.; Pellikka, P.A.; Cha, S.S.; Oh, J.K.; Ommen, S.R. Left atrial index is a predictor of exercise capacity in patients with hypertrophic cardiomyopathy. J. Am. Soc. Echocardiogr. 2005, 18, 1373-1380. [CrossRef] [PubMed]

7. Elliott, P.M.; Anastasakis, A.; Borger, M.A.; Borggrefe, M.; Cecchi, F.; Charron, P.; Hagege, A.A.; Lafont, A.; Limongelli, G.; Mahrholdt HMcKenna, W.J.; et al. 2014 ESC Guidelines on diagnosis and management of hypertrophic cardiomyopathy: The Task Force for the Diagnosis and Management of Hypertrophic Cardiomyopathy of the European Society of Cardiology (ESC). Eur. Heart J. 2014, 35, 2733-2779. [CrossRef] [PubMed]

8. Gersh, B.J.; Maron, B.J.; Bonow, R.O.; Dearani, J.A.; Fifer, M.A.; Link, M.S.; Naidu, S.S.; Nishimura, R.A.; Ommen, S.R.; Rakowski, H.; et al. 2011 ACCF/AHA guideline for the diagnosis and treatment of hypertrophic cardiomyopathy: Executive summary: A report of the American College of Cardiology Foundation/American Heart Association Task Force on Practice Guidelines. Circulation 2011, 124, 2761-2796. [CrossRef] [PubMed] 
9. Sorajja, P.; Allison, T.; Hayes, C.; Nishimura, R.A.; Lam, C.S.; Ommen, S.R. Prognostic utility of metabolic exercise testing in minimally symptomatic patients with obstructive hypertrophic cardiomyopathy. Am. J. Cardiol. 2012, 109, 1494-1498. [CrossRef] [PubMed]

10. Masri, A.; Pierson, L.M.; Smedira, N.G.; Agarwal, S.; Lytle, B.W.; Naji, P.; Thamilarasan, M.; Lever, H.M.; Cho, L.S.; Desai, M.Y. Predictors of long-term outcomes in patients with hypertrophic cardiomyopathy undergoing cardiopulmonary stress testing and echocardiography. Am. Heart J. 2015, 169, 684-692. [CrossRef] [PubMed]

11. Magri, D.; Re, F.; Limongelli, G.; Agostoni, P.; Zachara, E.; Correale, M.; Mastromarino, V.; Santolamazza, C.; Casenghi, M.; Pacileo, G.; et al. Heart Failure Progression in Hypertrophic Cardiomyopathy- Possible Insights From Cardiopulmonary Exercise Testing. Circ. J. 2016, 80, 2204-2211. [CrossRef] [PubMed]

12. Coats, C.J.; Rantell, K.; Bartnik, A.; Patel, A.; Mist, B.; McKenna, W.J.; Elliott, P.M. Cardiopulmonary Exercise Testing and Prognosis in Hypertrophic Cardiomyopathy. Circ. Heart Fail. 2015, 8, 1022-1031. [CrossRef] [PubMed]

13. Finocchiaro, G.; Haddad, F.; Knowles, J.W.; Caleshu, C.; Pavlovic, A.; Homburger, J.; Shmargad, Y.; Sinagra, G.; Magavern, E.; Wong, M.; et al. Cardiopulmonary responses and prognosis in hypertrophic cardiomyopathy: A potential role for comprehensive noninvasive hemodynamic assessment. JACC Heart Fail. 2015, 3, 408-418. [CrossRef] [PubMed]

14. Efthimiadis, G.K.; Giannakoulas, G.; Parcharidou, D.G.; Pagourelias, E.D.; Kouidi, E.J.; Spanos, G.; Kamperidis, V.; Gavrielides, S.; Karvounis, H.; Styliadis, I.; et al. Chronotropic incompetence and its relation to exercise intolerance in hypertrophic cardiomyopathy. Int. J. Cardiol. 2011, 153, 179-184. [CrossRef] [PubMed]

15. Sharma, S.; Elliott, P.; Whyte, G.; Jones, S.; Mahon, N.; Whipp, B.; McKenna, W.J. Utility of cardiopulmonary exercise in the assessment of clinical determinants of functional capacity in hypertrophic cardiomyopathy. Am. J. Cardiol. 2000, 86, 162-168. [CrossRef]

16. Desai, M.Y.; Bhonsale, A.; Patel, P.; Naji, P.; Smedira, N.G.; Thamilarasan, M.; Lytle, B.W.; Lever, H.M. Exercise echocardiography in asymptomatic HCM: Exercise capacity, and not LV outflow tract gradient predicts long-term outcomes. JACC Cardiovasc. Imaging 2014, 7, 26-36. [CrossRef] [PubMed]

17. Geske, J.B.; Ong, K.C.; Siontis, K.C.; Hebl, V.B.; Ackerman, M.J.; Hodge, D.O.; Miller, V.M.; Nishimura, R.A.; Oh, J.K.; Schaff, H.V.; et al. Women with hypertrophic cardiomyopathy have worse survival. Eur. Heart J. 2017, 38, 3434-3440. [CrossRef] [PubMed]

18. Squires, R.W.; Allison, T.G.; Johnson, B.D.; Gau, G.T. Non-physician supervision of cardiopulmonary exercise testing in chronic heart failure: Safety and results of a preliminary investigation. J. Cardiopulm. Rehabil. 1999, 19, 249-253. [CrossRef] [PubMed]

19. Larsen, C.M.; Ball, C.A.; Hebl, V.B.; Ong, K.C.; Siontis, K.C.; Olson, T.P.; Ackerman, M.J.; Ommen, S.R.; Allison, T.G.; Geske, J.B. Effect of Body Mass Index on Exercise Capacity in Patients With Hypertrophic Cardiomyopathy. Am. J. Cardiol. 2017, 121, 100-106. [CrossRef] [PubMed]

20. Myers, J.; Kaminsky, L.A.; Lima, R.; Christle, J.W.; Ashley, E.; Arena, R. A Reference Equation for Normal Standards for VO2 Max: Analysis from the Fitness Registry and the Importance of Exercise National Database (FRIEND Registry). Prog. Cardiovasc. Dis. 2017, 60, 21-29. [CrossRef] [PubMed]

21. Magri, D.; Agostoni, P.; Cauti, F.M.; Musumeci, B.; Egidy Assenza, G.; De Cecco, C.N.; Muscogiuri, G.; Maruotti, A.; Ricotta, A.; Pagannone, E.; et al. Determinants of peak oxygen uptake in patients with hypertrophic cardiomyopathy: A single-center study. Intern. Emerg. Med. 2014, 9, 293-302. [CrossRef] [PubMed]

22. Sharma, S.; Firoozi, S.; McKenna, W.J. Value of exercise testing in assessing clinical state and prognosis in hypertrophic cardiomyopathy. Cardiol. Rev. 2001, 9, 70-76. [CrossRef] [PubMed]

23. Keteyian, S.J.; Kitzman, D.; Zannad, F.; Landzberg, J.; Arnold, J.M.; Brubaker, P.; Brawner, C.A.; Bensimhon, D.; Hellkamp, A.S.; Ewald, G. Predicting Maximal Heart Rate in Heart Failure Patients Receiving Beta-Blockade Therapy. Med. Sci. Sports Exerc. 2012, 44, 371. [CrossRef] [PubMed]

24. Miller, M.R.; Hankinson, J.; Brusasco, V.; Burgos, F.; Casaburi, R.; Coates, A.; Crapo, R.; Enright, P.; van der Grinten, C.P.; Gustafsson, P.; et al. Standardisation of spirometry. Eur. Respir. J. 2005, 26, 319-338. [CrossRef] [PubMed] 
25. Wang, Y.; Wang, J.; Zou, Y.; Bao, J.; Sun, K.; Zhu, L.; Tian, T.; Shen, H.; Zhou, X.; Ahmad, F.; et al. Female sex is associated with worse prognosis in patients with hypertrophic cardiomyopathy in China. PLoS ONE 2014, 9, e102969. [CrossRef] [PubMed]

26. Olivotto, I.; Maron, M.S.; Adabag, A.S.; Casey, S.A.; Vargiu, D.; Link, M.S.; Udelson, J.E.; Cecchi, F.; Maron, B.J. Gender-related differences in the clinical presentation and outcome of hypertrophic cardiomyopathy. J. Am. Coll. Cardiol. 2005, 46, 480-487. [CrossRef] [PubMed]

27. Mosca, L.; Ferris, A.; Fabunmi, R.; Robertson, R.M.; American Heart, A. Tracking women's awareness of heart disease: An American Heart Association national study. Circulation 2004, 109, 573-579. [CrossRef] [PubMed]

28. Okayama, S.; Soeda, T.; Kawakami, R.; Takami, Y.; Somekawa, S.; Ueda, T.; Sugawara, Y.; Matsumoto, T.; Sung, J.H.; Nishida, T.; et al. Evaluation of coronary artery disease and cardiac morphology and function in patients with hypertrophic cardiomyopathy, using cardiac computed tomography. Heart Vessels 2015, 30, 28-35. [CrossRef] [PubMed]

29. Bugger, H.; Abel, E.D. Molecular mechanisms of diabetic cardiomyopathy. Diabetologia 2014, 57, 660-671. [CrossRef] [PubMed]

30. Boyer, J.K.; Thanigaraj, S.; Schechtman, K.B.; Perez, J.E. Prevalence of ventricular diastolic dysfunction in asymptomatic, normotensive patients with diabetes mellitus. Am. J. Cardiol. 2004, 93, 870-875. [CrossRef] [PubMed]

31. Aneja, A.; Tang, W.H.; Bansilal, S.; Garcia, M.J.; Farkouh, M.E. Diabetic cardiomyopathy: Insights into pathogenesis, diagnostic challenges, and therapeutic options. Am. J. Med. 2008, 121, 748-757. [CrossRef] [PubMed]

32. Norton, G.R.; Candy, G.; Woodiwiss, A.J. Aminoguanidine prevents the decreased myocardial compliance produced by streptozotocin-induced diabetes mellitus in rats. Circulation 1996, 93, 1905-1912. [CrossRef] [PubMed]

33. Wang, J.; Buergler, J.M.; Veerasamy, K.; Ashton, Y.P.; Nagueh, S.F. Delayed untwisting: The mechanistic link between dynamic obstruction and exercise tolerance in patients with hypertrophic obstructive cardiomyopathy. J. Am. Coll. Cardiol. 2009, 54, 1326-1334. [CrossRef] [PubMed]

34. Ha, J.W.; Cho, J.R.; Kim, J.M.; Ahn, J.A.; Choi, E.Y.; Kang, S.M.; Rim, S.J.; Chung, N. Tissue Doppler-derived indices predict exercise capacity in patients with apical hypertrophic cardiomyopathy. Chest 2005, 128, 3428-3433. [CrossRef] [PubMed]

35. Matsumura, Y.; Elliott, P.M.; Virdee, M.S.; Sorajja, P.; Doi, Y.; McKenna, W.J. Left ventricular diastolic function assessed using Doppler tissue imaging in patients with hypertrophic cardiomyopathy: Relation to symptoms and exercise capacity. Heart 2002, 87, 247-251. [CrossRef] [PubMed]

36. Matsumoto, A.Y.; Arteaga, E.; Ianni, B.M.; Braga, A.M.; Buck, P.C.; Mady, C. Relationships among exercise capacity, hypertrophy, and left ventricular diastolic function in nonobstructive hypertrophic cardiomyopathy. Am. Heart J. 2005, 150, 144-149. [CrossRef] [PubMed]

37. Maeder, M.T.; Thompson, B.R.; Brunner-La Rocca, H.P.; Kaye, D.M. Hemodynamic basis of exercise limitation in patients with heart failure and normal ejection fraction. J. Am. Coll. Cardiol. 2010, 56, 855-863. [CrossRef] [PubMed]

38. Borlaug, B.A.; Nishimura, R.A.; Sorajja, P.; Lam, C.S.; Redfield, M.M. Exercise hemodynamics enhance diagnosis of early heart failure with preserved ejection fraction. Circ. Heart Fail. 2010, 3, 588-595. [CrossRef] [PubMed]

(C) 2018 by the authors. Licensee MDPI, Basel, Switzerland. This article is an open access article distributed under the terms and conditions of the Creative Commons Attribution (CC BY) license (http:/ / creativecommons.org/licenses/by/4.0/). 